\title{
PILOT EXPERIENCE TO INCREASE THE ENVIRONMENTAL AWARENESS OF YOUNG STUDENTS (12-18 YEARS) THROUGH INNOVATING FORMATION BY UPM RESEARCHERS IN THE CLASSROOM
}

\author{
C. Calderón-Guerrero, M. Martínez Núñez, S. Sastre Merino, M. Marchamalo \\ Universidad Politécnica de Madrid (SPAIN)
}

\begin{abstract}
The Dive \& Breath project is part of the Madrid Deep Demonstration (DD) portfolio and it is supported by the Spanish Climate KIC Education Office (CK). The project promotes the participatory innovation of teenagers and incorporates experiential learning to guide them to the collective design and implementation of a network of the environmental quality sensors of their neighbourhood (air and water monitoring). The process is carried out by professors and is applied to pilot groups of students, and later, the students, based on their experience and learning, teach other students. This way, the replication phase of the innovative methodologies in the educational field is introduced. The interdisciplinary approach merges through games, observation, and data collection. The project has used ICTs tools, due to COVID circumstances. The practical learning has been developed through DIY (construction of sensors) and citizen science. The proposal incorporates innovative learning methodologies such as experiential learning, based on a collective construction of knowledge that brings together all the agents involved. This approach transcends the usual proposals in the educational field. In this case, from the design phase, diverse visions come together to build a conceptual framework on which practical knowledge is built through experience.
\end{abstract}

Further on, Service-learning for UPM students, in the context of secondary education, boots enormous potential for university students to interact with teenagers, performing a service of solidarity while learning and developing technical, transversal, social and ethical skills that will be of great value in their professional and personal development. Among the advantages of this approach, it highlights and increases their motivation and social awareness.

The project is a fully scalable proposal with remarkable impact in the target area of Madrid City (Southern Districts). It is developed in critical districts and supported by key stakeholders for further expansion. Such as, the neighbour's platform "Nave Boetticher" (NB) that ensures the involvement of education leaders from 2 secondary education centres in the neighbourhood (Montserrat \& Comunidad infantil). The UPM group of university professor and researchers would train young students promoting the construction and monitoring of sensors for air \& water quality. D\&B data will work in synergy with Spanish Climate KIC Education Office, and MonteMadrid foundation, to promote the spread of Young Innovators experiment in other target areas in Spain. Climate-KIC has played the role as an orchestrator of networks to facilitate and shared investment of deeper system change and on a larger scale and offering guidance and support due to their knowledge and experience. Climate-KIC has offered interesting innovative tools to be applied to our project and could facilitate connections with other Spanish colleagues who are working in a similar path as us. We totally agree in the fact that to achieve real system change, we all need to work together to gain recognition of the challenges and necessary investment.

The potential value (monetary, non-monetary) that is associated with these actions provides: 1) empowerment of the disadvantaged population, 2) promotion of the connection between neighbours and their territory, 3 ) creation of a replicable and sustainable pedagogical model of learning and service and 4) promotion of climate leadership among young people.

Keywords: Secondary Education, Service-learning, Climate-KIC, Madrid Deep Demonstration, environmental pollution, biomonitoring, urban trees, water, air pollutants.

\section{INTRODUCTION}

This manuscript summarizes the pilot experience of citizen science promoting the empowerment of urban young leaders regarding their environment (air and water quality), through innovating formation and increased awareness. This project has been carried out within the framework of the Young 
Innovators (EIT-Climate KIC) program, applying their program's methodology and available at their website [1]. Dive \& Breath Data (D\&B Data) is conceived as the first chapter of a series of innovative experimental modules to be developed for young changemakers (12-18 years). The series is entitled "Neighbourhood Ecology" and D\&B data aims to enrol teenagers as "water and air quality inspectors".

This project has been designed for vulnerable neighbourhoods, where the different educational and social ratios are remarkable. These kinds of educational programs are very important to avoid conflicts, mental health problems, and even juvenile delinquency [2]. The program promotes scientific knowledge, who plays the main role on this project, but it is also supported by environmental technology and programming to face social and environmental challenges. Additionally, a teacher booklet has been elaborated with the aim to support teachers during the workshops and it has been adapted to Spanish education system and Madrid Deep Demo objectives [3]. This guide has been designed for teachers interested in developing the project (D\&BData)" project at school. This document offers detailed information about the project, as well as the resources and dynamics that support the teaching work in the development of this experience. The information and materials produced within the project are available at project websites (in Spanish [4] and summarized in English [5]).

Service Learning is a way of learning during the development of an action, which in turn represents a service to the community. In service-learning, students work in relation to an objective or problem in their environment, developing a proposal that puts into play the knowledge, attitudes, and values that they have worked on, or developing them for this purpose [6]. In this project, service-learning is developed in two levels. 1) At University level. Last year undergraduate and MSc students are trained in the project to be able to guide and accompany the groups in the classroom in the development of sensor construction sessions and the understanding of the role of $\mathrm{CO}_{2}$ absorption and heavy metal fixation by urban trees [7] 2) In schools: During the experience, the students develop tools, knowledge, and skills in relation to the common problem of pollution in big cities [8] [9], one of the main purposes of the project. These actions represent an important reinforcement in the awareness and assessment of urban trees in the city of Madrid [10] [11], the effects of air pollution on trees species in large cities [12] and the importance of the restoration of degraded spaces through urban trees [13]. "Neighbourhood ecology: water and air quality Inspectors: D\&B Data" is based on a theoretical-practical group-learning process. The working process is developed by a cooperative group. Basically, it consists in the practical principle of "we work with other people, we learn with others, we distribute tasks, and we carry them out". This way, the result of what has been achieved is a collective process. Learning as a team, experiencing teamwork relationships are conceived as a part of the learning process that we try to develop in this program and that we have implemented in other Young students' actions at schools [14].

Another pillar of this learning approach is the concept of citizen science, which follows the researchbased learning approach. Students can also approach learning from an experimental, trialerror/success, and analysis approach. An approach that has to do with the scientific method, of generating starting hypotheses, developing an experimentation phase from which they deduce the conclusions and communicate them to relatives, friends, and different social agents, that can rely on the knowledge generated by them.

\section{METHODOLOGY}

The lectures and workshops of the program were given to 2 high schools, with a total number of 14 sessions ( 7 sessions in each high school) and 28 hours of teaching. 37 students and 6 high school's teachers participated in the pilot project.

\subsection{Citizen-science based learning.}

The way of advancing technical and scientific knowledge in recent centuries has been done through the so-called "scientific method". A learning process based on observation, hypothesis design / problem statements and experimentation that obtains information, which, when analysed, allows us to obtain a conclusion and verify the truth or falsity of that idea. In this second case, the starting hypothesis is reformulated. In any case, the results are shared within the scientific community [15]. Research is usually imagined / associated with laboratories at universities or research centres, in which only researchers oversee carrying out the experiments. However, it is becoming more frequent that it is open to citizens, and they become participants both in the design and process of experimentation and analysis of the information. In this way, scientific knowledge is democratized, more accessible and closer to citizens of different ages, as well as the tools and working methods typical of these disciplines. Social knowledge, attached to territorial realities, and technical knowledge are combined, thus taking new 
dimensions of research. All this supported by new technologies, which overcomes physical barriers and allows an exchange and rapprochement of knowledge. D\&B Data project, within Neighbourhood Ecology carry out an extreme Citizen Science proposal (Figure 1), where students accompanied by teachers and researchers jointly define the object of the research, developing their own analysis instruments (sensors) and collecting environmental information. This information was divulged and available to the rest of the community.

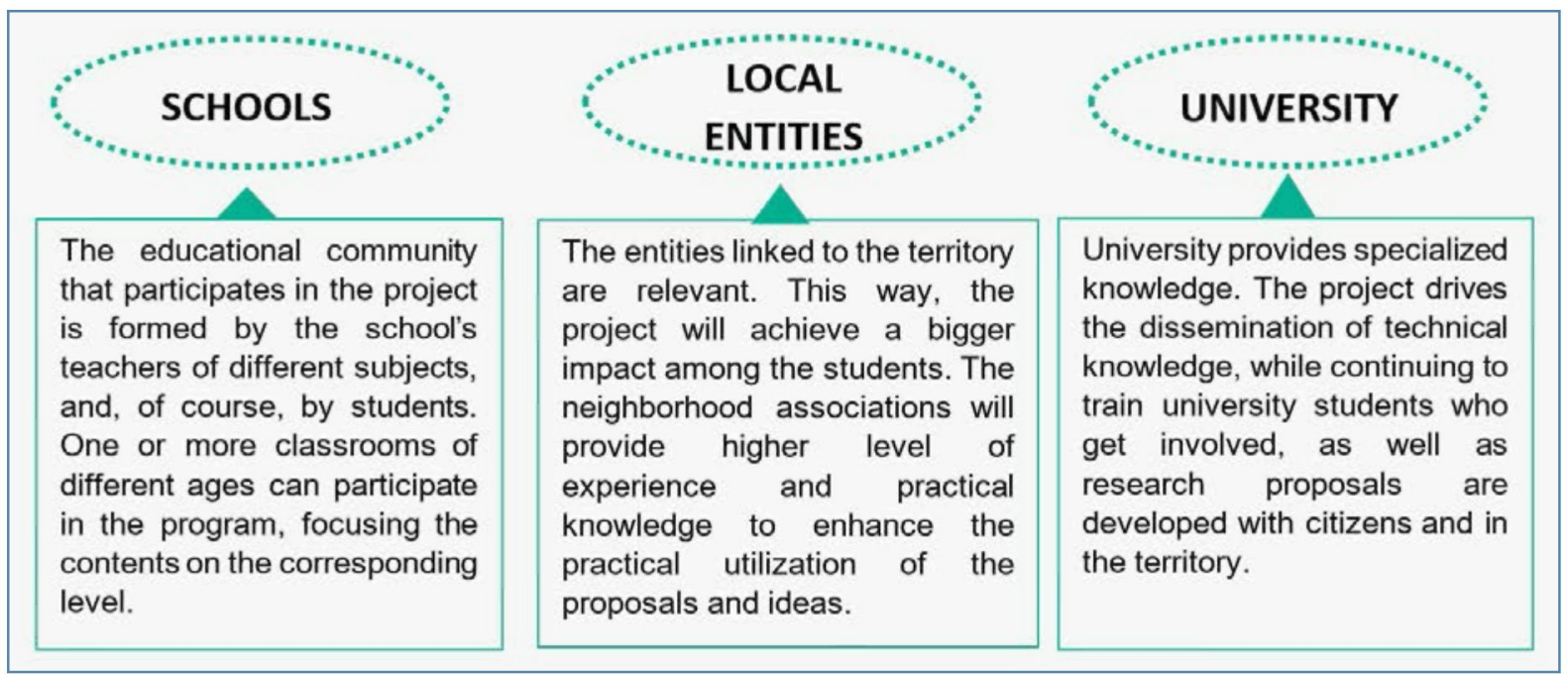

Figure 1. Citizen-science based learning stakeholders.

D\&B Data team has worked within the following rationale:

- The team formed by local promoters + University researchers formulate each session.

- Each week, the whole team, including school's teachers, meet and adapt the formulated session to every class group.

- Sessions are carried out in every class and school.

- Materials are uploaded and shared in a common Google Drive, accessible to all participants (students and teachers) and incorporated to the project's website.

Table 1. List of sessions.

\begin{tabular}{l|l}
\hline \multicolumn{1}{c|}{ Sessions } & \multicolumn{1}{c}{ Title } \\
\hline SESSION 0 & PROJECT PRESENTATION AND WORKING GROUPS FORMATION \\
\hline SESSION 1 & WHAT DO WE KNOW ABOUT OUR ENVIRONMENT? \\
\hline SESSION 2 & INSPECTORS OF THE ENVIRONMENT \\
\hline SESSION 3 & SENSOR-MAKING 1: BEGINNING SENSOR CONSTRUCTION \\
\hline SESSION 4 & YOUNG CLIMATHON (MEEETING AND WORKING WITH OTHER YOUNG INNOVATORS) \\
\hline SESSION 5 & SENSOR-MAKING 1: INSTALATION AND MONITORING \\
\hline SESSION 6 & ANALYSIS AND CONCLUSIONS \\
\hline SESSION 7 & EVALUATION \\
\hline ALL THE TIME & COMMUNICATION OF PARTIAL RESULTS \\
\hline
\end{tabular}

The planning of the sessions (table 1) was altered by the delay in the availability of the measurement equipment during the COVID pandemic. Furthermore, the sensor-making part had to be readjusted to the number of sensors to be carried out in each case. The experience after conducting the workshops advised to think about mounting a sensor in two sessions (depending on its complexity). 


\subsection{Transversal approach}

The approach to a work based on experimentation and development of research projects allows to creatively approach different contents and subjects of scientific-technical content: Technology, Biology, Physics, Mathematics. But also, the diffusion and dissemination of the contents were available and useful to other subjects, such as Spanish language and Literature, or English Language. The work proposal in the classroom was cooperative work. Learning is not a matter that takes place in isolation and individually, but is easier and more stimulating, if it is done in a team [14]. Cooperative work in the classroom consisted of a cooperative work to achieve common goals. These groups were organized for a maximum of five members and each of them adopted specific roles or tasks within the group, even if the responsibility was shared.

The steps for implementing cooperative groups were:

- DISTRIBUTION OF THE CLASSROOM IN GROUPS. The groups are made up of $4 / 5$ boys or girls. They choose themselves which group they want to be in, but they have to take into account the limit of people per group.

- GROUP COHESION: Group cohesion and identity are worked on. For this, there are different dynamics that can contribute to improve and enhance group cohesion and create their own identity.

- ASSIGNING ROLES: In cooperative work we work with the assignment of roles, where each of the boys / girls are responsible for a task, although for it to succeed, collective responsibility is necessary. The roles are: spokesperson, facilitator, reporter and doer.

- MONITORING AND EVALUATION: We evaluate, teachers and groups, how the work is developing and if the

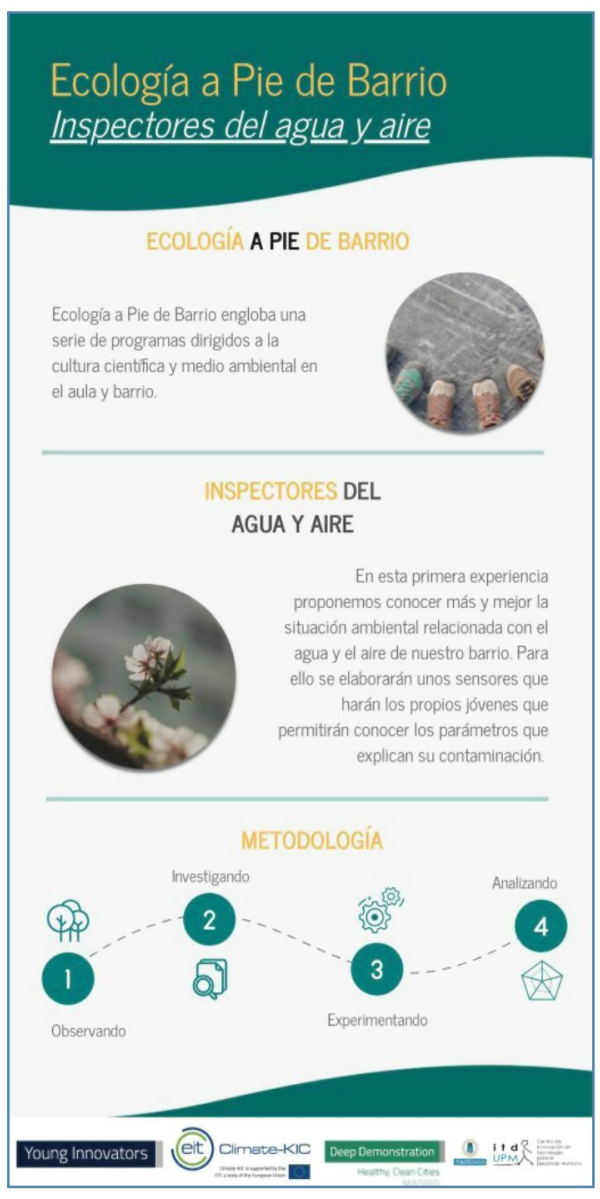

Figure 2. Project outlook and methodology (in Spanish). objectives identified at the beginning are being achieved.

\subsection{Teacher's booklet methodology}

This document was arranged and updated according to the experience carried out from September to December 2020 from two schools of primary and secondary education located in Southern Madrid: "Nuestra Señora de Montserrat" in Usera district and "Comunidad Infanti"' in Villaverde district. Given the context and situation in which the project was developed in 2020 , the experience was been developed as B-learning. Due to social distance and very limited possibilities to work in teams and carrying out practical activities of measuring and monitoring outdoor.

The Young Innovators workshops were developed in the framework of Madrid Deep Demo initiative, collaborating with local partners and associations involved in the initiative in these two high-priority districts of Madrid. This city was selected as one of the 15 demonstrator cities to become carbon neutral by 2030, within the framework of the EIT Climate-KIC program Deep Demonstrations of Healthy \& Clean Cities. For this purpose, the Government of the City, together with Climate KIC partners (UPM, Ferrovial, etc), as well as citizen organizations and associations for the implementation of actions related to mobility, urban renaturation, and improvement of neighbourhoods, among others, were organized in a participatory co-creation process to satisfy the common interest of Madrid citizens.

"Neighbourhood Ecology" aims to offer to the school environment, a space for learning and experimentation, a place where action occurs and where young and old can learn together, sharing the place where students live, assessed by tools and techniques of systems-thinking and scientific research, for a better understanding and to develop creative and collaborative actions for the local environment improvement, by supporting small actions that sum up to create greater networks of action. Acting locally, immediately and closely, to tackle a challenge that is global and common. 


\section{RESULTS}

The many outputs from this project have been: 1) a handbook document, 2) a "Teacher's booklet (TB)" document, 3) an Open Blog, and 4) a quality evaluation questionnaire to assure the level of satisfaction of student and professors after each one of the 14 sessions. These results try to give answers to improve air quality in the local neighbourhood and were based in:

- system \& stakeholders mapping

- alternatives (ocean of opportunities)

- solutions design (map design)

- sharing and connecting with other "Climathons" meetings (Valencia city) and civil organizations.

All outputs of the pilot experience could be transferred and scaled to other schools, cities, and countries.

\subsection{Handbook (H)}

This document contains all details about the activities followed during each session, such as the organization of groups, the settings of the Jamboard software employed and the supervision by the teachers of the "oceans of opportunities" tool (Figure 3). For each session, the methodology and duration of each activity was provided.

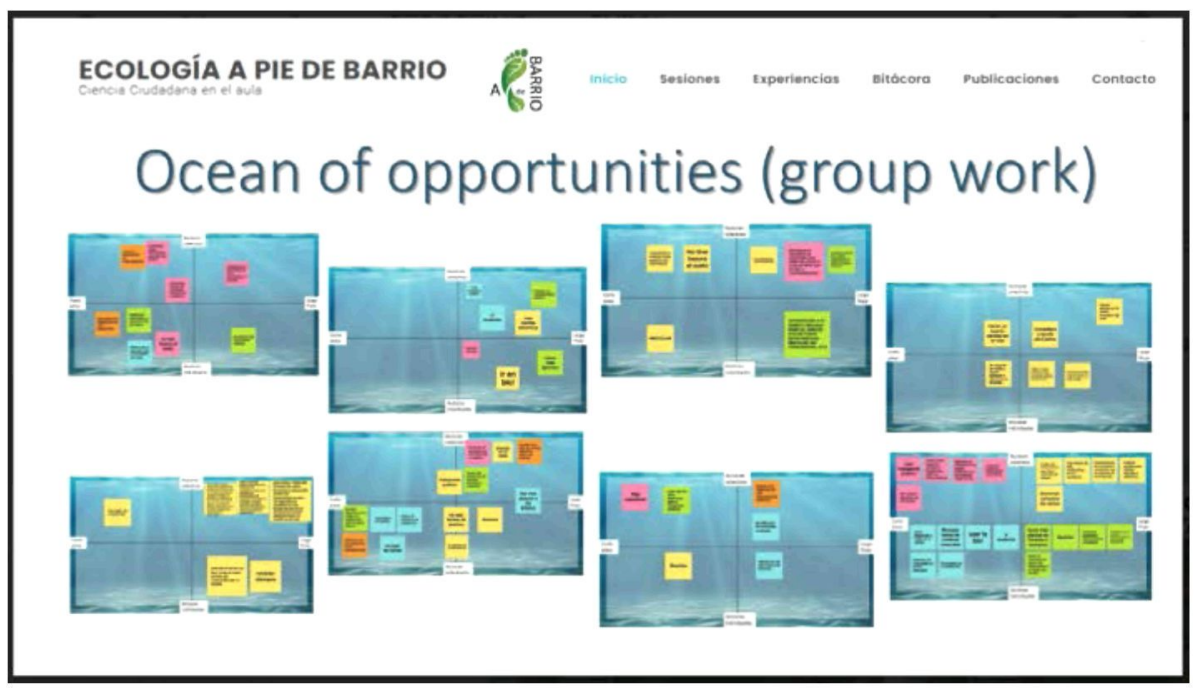

Figure 3. Example of the "Oceans of opportunities" alternatives tool

\subsection{Teacher's booklet (TB)}

This 24-pages document was elaborated from the experience carried out from September to December 2020 (Figure 4) and contained the highlights of the program to cover the following aims:

- Develop an analytical and reflective vision about the environmental situation of their closest environment (the neighbourhood).

- Promote scientific culture and systems-thinking through experimentation in the classroom and outside of it.

- Connect with entities and initiatives in their surroundings that work for the environmental improvement of their neighbourhoods.

- Develop digital and scientific competences, through the development of sensors made by themselves.

- Encourage creativity and cooperation in the classroom to address common environmental challenges.

- Encourage their empowerment and initiative towards the ecosystem improvement of their neighbourhood. 


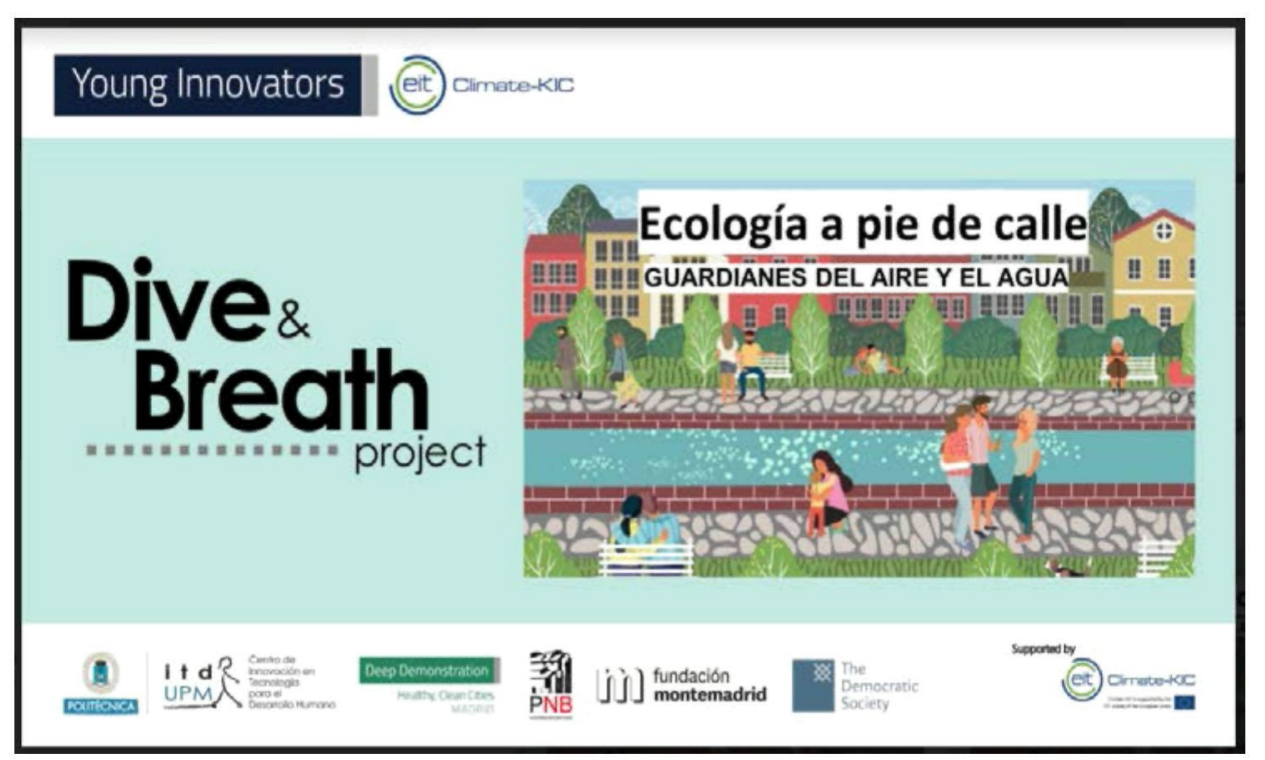

Figure 4. Cover from the teacher's booklet.

\subsection{Open Blog (OB)}

The objective of exchange the information, outputs and experiences with other students, educational centres and organizations was accomplished by the development of an open blog, under the UPM network (Figure 5).

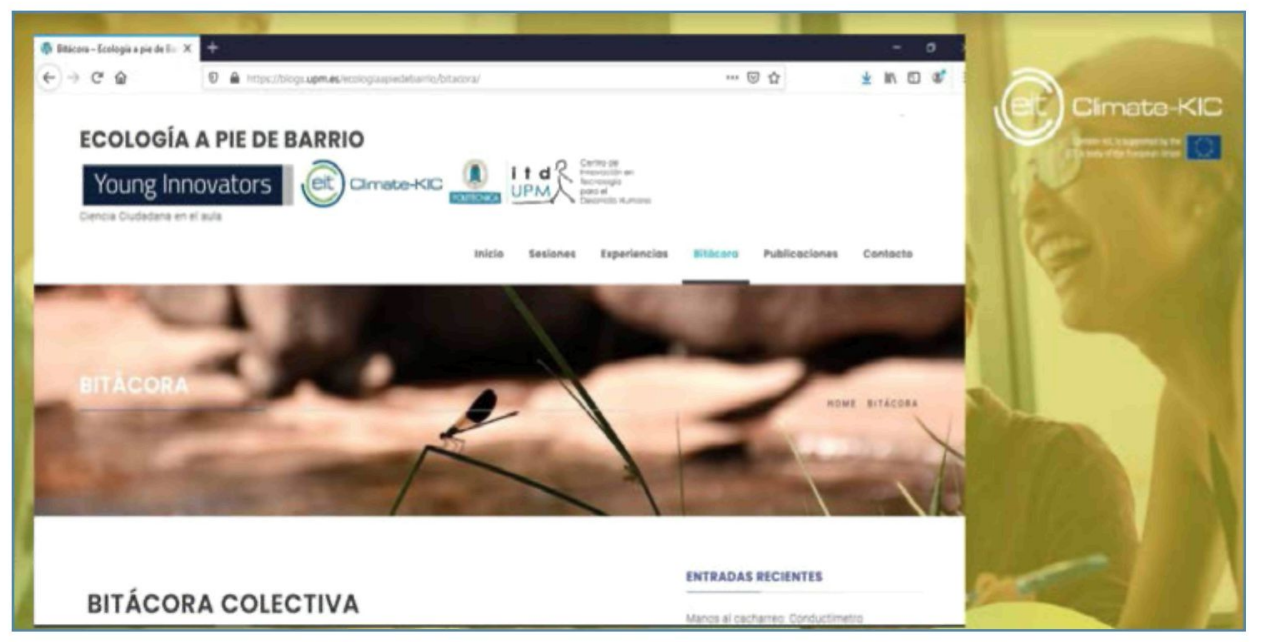

Figure 5. "Ecología a pie de barrio" open blog at https://blogs.upm.es/ecologiaapiedebarrio/

\subsection{Quality questionnaires (QQ)}

Satisfaction with the program was high after surveys conducted at the end of the activities, showing higher awareness, knowledge and commitment towards air and water problems. Despite COVID context, 2 high schools committed with Young Innovators Program and other schools showed interest to scale the program in the frame of Madrid Deep Demonstration in 2021.

An example of the results of the surveys conducted are displayed in Figures 6 and 7. 


\section{What did you find most interesting about today's activity?}

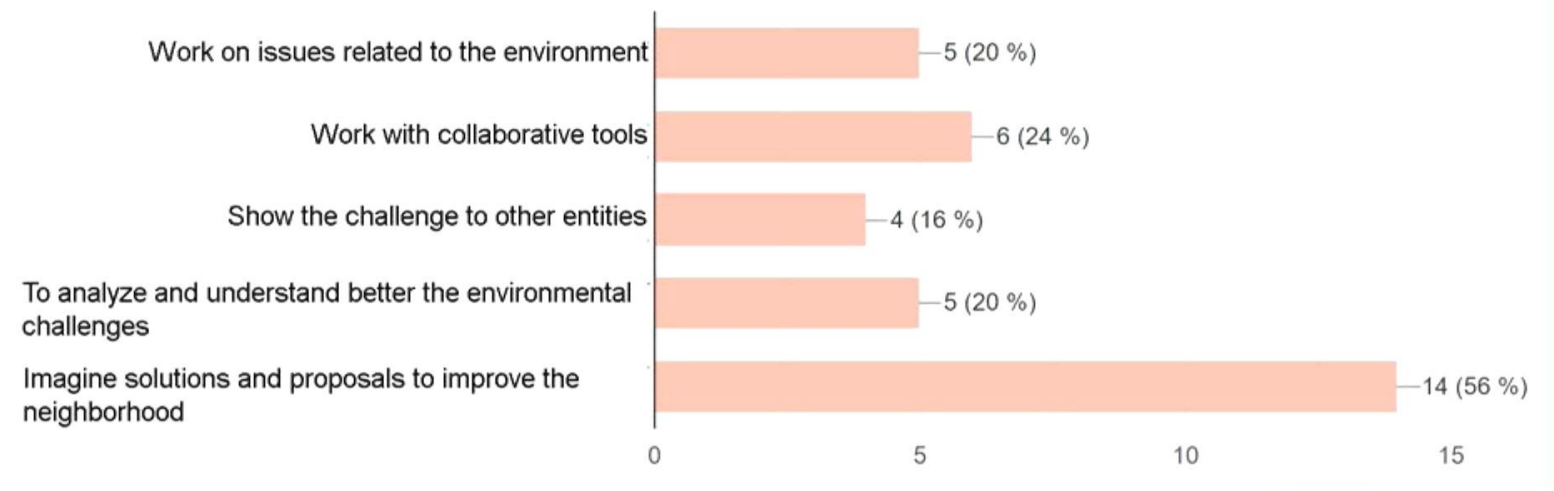

Figure 6. Answers to the question 3 of the Session n. 4 "Young Climathon" (1-day workshop with other young innovators students in Valencia (Spain)) quality evaluation questionnaire. $(N=34)$

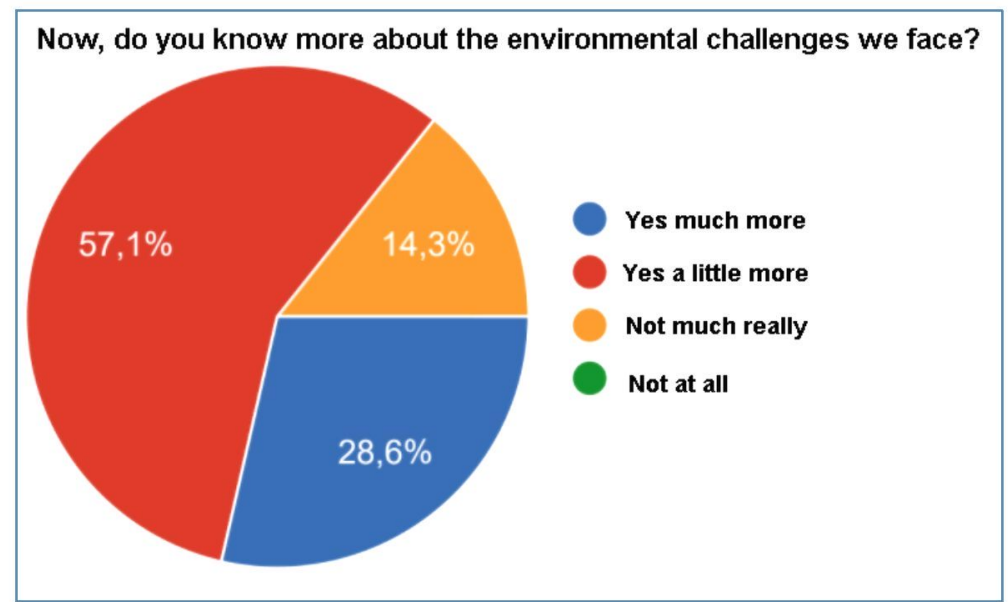

Figure 7. Answers to the question 5 of the Session n. 4 "Young Climathon" (1-day workshop with other young innovators students in Valencia (Spain)) quality evaluation questionnaire. $(N=34)$

\section{DISCUSSION}

The project has reached a $100 \%$ level of completeness, overcoming the grave pandemic situation that has affected worldwide and with dramatic consequences in Southern Madrid districts, under confinement during most of the teaching action. The main outputs, $100 \%$ accomplished, of the project were:

- Transferable pilot experience of citizen science (OUT 201904-O01) promoting the empowerment of urban young leaders about their environment (air and water quality) through innovating formation and increased awareness. The program was imparted in 2 sigh schools, with a total number of 14 sessions ( 7 sessions in each School) and 28 hours of teaching. 37 students and 6 High School teachers participated in the pilot project.

- Teacher training booklet in English and Spanish (DEL 201904-D02) for the expansion of the project.

- Handbook on air and water quality monitoring (DEL 201904-D02) adapted to the Spanish secondary education curricula, targeting organizations and teams interested in the local expansion of the program. This manual is adapted to the reality of Spanish schools and framed in the Madrid Deep Demo project. For these reasons, it is written in Spanish, with an English summary. 
- A great impact event was developed in the frame or the project: Young Climathon Madrid 2020Empowering the next generation of climate leaders- Madrid, took place in 13 nov 2020 in both participating Schools with relevant impact in participation and media (EVR 201904-E02)

- Establishment of a working team based on the alliance between 3 local organisations (Plataforma Nave Boetticher, Fundación Montemadrid and Democratic Society), 2 Schools (Montserrat and Comunidad Infantil) and the Universidad Politecnica de Madrid (UPM) in the frame of Madrid Deep Demonstration project.

- Future Financial Participation of EIT Climate-KIC Holding BV, as the Project Team has supported the Green Deal proposal prepared by the Climate KIC Education Team. (KAVA 4.1.5)

- Future Financial sustainability, through the development of contacts with potential funders and partners, such as Fundación Montemadrid (co-founder in 2020 D\&B Data project), Fundación Telefónica, and "Teachers for Future".

The main risk for the project has been, as identified in project formulation, the COVID-19 pandemic. The initial proposal of D\&B Data project was formulated to be developed in situ in a classroom format. Although it is in the classroom, its environment, and "field trips" excursions where the project could reach its greatest meaning and potential, it has been successfully overcome, by adapting the project to a BLearning approach. This initiative is linked to the reality of the neighbourhood. Therefore, it requires, necessarily, direct contact with the most immediate space. Despite of all these circumstances, the dynamics of the sessions, showed an active participation of the students and an interaction between the work groups proposed. The Zoom virtual sessions helped to overcome part of the distance, though the naturalness, proximity and possibility of a conversation and creation of ideas between students was partially restricted. The physical distance was imposed in the health context in which this proposal has been socially developed. Therefore, a mainly online format has been successfully followed, adapting the sessions to this blended format, and presence was limited to what was strictly necessary.

\section{CONCLUSIONS}

This program was carried out at particularly vulnerable neighbourhoods, where the different educational and social figures suggest the need to innovate and rethink social and educational strategies and procedures. Education is a social elevator, which can improve the quality of life of these neighbours and reverse the systemic social inequalities of the territories. A greater effort is necessary to offer the same opportunities to teenagers. This way, knowledge could be accessible to support the educational and social development.

The potential value (monetary, non-monetary) that is associated with these actions have tried to provide: 1) empowerment of the disadvantaged population, 2) promotion of the connection between neighbours and their territory, 3 ) creation of a replicable and sustainable pedagogical model of learning (and service learning developed by 2 UPM students) and 4) promotion of climate leadership among young people.

The overall evaluation is highly positive, as the action is set to grow and be expanded in 2021 in the framework of Madrid Deep Demonstration project.

\section{ACKNOWLEDGEMENTS}

We want to thank for their contribution and assistance to Ms. Isabel Ochoa and Mr. Manuel Alméstar, and to Plataforma Nave Boetticher, Fundación Montemadrid and Democratic Society for their personal/financial support, and finally, to the students and teachers of the Montserrat and Comunidad Infantil for their engagement and collaboration.

\section{REFERENCES}

[1] EIT Climate-KIC, "Young Innovators. Climate action for future generations". Retrieved from URL: https://younginnovators.climate-kic.org/

[2] M.A. Alcázar-Córcoles, J.C. Bouso-Saiz, J. Revuelta, C.A. Hidalgo Rasmussen, E. Ramírez Lira, C. Calderón-Guerrero, "Juvenile delinquents in Toledo (Spain) from 2001 to 2012: Psychosocial, educational and criminal characteristics". Spanish Journal of Legal Medicine. Elsevier, vol. 45, no. 3, pp. 98-107. 2019. 
[3] E. Caro Gómez, "Estudios de caso". Cuadernos de estrategia, no. 206, pp. 301-358. 2020.

[4] Universidad Politécnica de Madrid (UPM). "Ecología a pie de barrio". Retrieved from URL: https://blogs.upm.es/ecologiaapiedebarrio/

[5] Technical University of Madrid (UPM). "Young Innovators Madrid UPM". Retrieved from URL: https://blogs.upm.es/yimadridupm/

[6] J. Halberstadt, J.M. Timm, S. Kraus \& K. Gundolf. "Skills and knowledge management in higher education: how service learning can contribute to social entrepreneurial competence development". Journal of Knowledge Management. 2019.

[7] C. Calderón-Guerrero, F. Palao, "Estimación de la absorción de $\mathrm{CO}_{2}$ y fijación de metales pesados por parte del arbolado urbano de alineación de Pozuelo de Alarcón (Madrid). Actas $7^{\circ}$ Congreso Iberoamericano de Parques y Jardines Públicos. pp.1-12. 2010.

[8] C. Calderón-Guerrero, MS Günthardt-Goerg, P Vollenweider, "Urban trees and air pollution: Quantitative and qualitative results from Madrid". Air Pollution and Climate Change at Contrasting Altitude and Latitude, 83. 2008.

[9] C. Calderón-Guerrero, "Urban trees and atmospheric pollutants in big cities: Effects in Madrid". (PhD. Thesis). Escuela Técnica Superior de Ingenieros de Montes, Forestal y Medio Natural. Universidad Politécnica de Madrid. 2014

[10] C. Calderón-Guerrero, J.A. Saiz de Omeñaca Gonzalez, J. Sastre, M.S. Günthardt-Göerg, "Urban trees and air quality ameloration in big cities. Effects in Madrid. El arbolado urbano y mejora de la calidad del aire en grandes ciudades. Efectos en Madrid". XIII World Forestry Congress proceedings / Actas XIII Congreso Forestal Mundial. 2009.

[11] C. Calderón-Guerrero, M. García Molina, F. Palao Núñez, A.B. López Martínez, J.A. Saiz de Omeñaca Gonzalez, "Gestión y beneficio de arbolado urbano del municipio de Pozuelo de Alarcón (Madrid)". XIII World Forestry Congress proceedings / Actas XIII Congreso Forestal Mundial. 2009.

[12] C. Calderón-Guerrero, M.S. Günthardt-Goerg, P. Vollenweider, "Foliar Symptoms Triggered by Ozone Stress in Irrigated Holm Oaks from the City of Madrid, Spain". PloS one, vol. 8, no. 7, pp. e69171. 2013.

[13] C. Calderón-Guerrero, "Restauración de espacios degradados por medio del arbolado urbano" (Chapter XV). In "Restauración de la cubierta vegetal y de espacios degradados en la región de la Macaronesia", J.C. Santamarta Cerezal \& J. Naranjo Borges editors. 2015.

[14] C Calderón-Guerrero, A Dronda, O Merino, "This smell of science, discovering the scientific method by the way of the essential oils and aromatic plants in the classroom". ICERI2019 Proceedings. 12th annual International Conference of Education. 2019.

[15] S.R. Shah, \& L.R. Martinez. "Current approaches in implementing citizen science in the classroom". Journal of microbiology \& biology education, vol. 17, n. 1, p. 17. 2016. 